social y la salud mental o emocional. También se planteó una pregunta aislada para investigar si las mujeres habían notado algún cambio en su salud general durante el último año.

Según los resultados, no se observaron diferencias significativas entre el grupo tratado y el grupo testigo en lo que respecta a salud general, vitalidad, salud mental, estado anímico y satisfacción sexual. Sí se detectó una ligera diferencia significativa en cuanto a la calidad del sueño, el funcionamiento físico y la presencia de dolores corporales al cabo de un año de tratamiento. Al cabo de tres años, sin embargo, no se advirtió diferencia alguna en ninguno de los parámetros estudiados. En mujeres de 50 a 54 años de edad con síntomas vasomotores moderados a graves al principio del estudio se observó una ligera mejoría de estos trastornos exclusivamente. En resumen, en el estudio aquí descrito no se detectó ningún efecto beneficioso que fuese clínicamente importante sobre los parámetros que se usaron para definir la calidad de la vida.

Hay quienes sostienen que pueden demorar un año o más en producirse los efectos favorables del tratamiento con estrógenos más progestágenos sobre los aspectos de la calidad de la vida que se ven definidos por la salud. No obstante, los resultados de este estudio no respaldan esta opinión, aunque no hay que descartar la posibilidad de que la ausencia de resultados significativos se haya debido a que al cabo de tres años de estudio la muestra era relativamente pequeña. (Hays J et al. Effects of estrogen plus progestin on health-related quality of life. $N$ Engl J Med 2003;348(19).)

\section{El tabaquismo de los padres y su efecto en la susceptibilidad de hijos menores de un año a las infecciones respiratorias bajas}

Se sabe que la exposición de los niños menores de un año al humo de tabaco se asocia con un mayor riesgo de infecciones respiratorias bajas, tales como bronquitis y neumonía, irritación del árbol respiratorio superior y una ligera pérdida de la función pulmonar, así como con nuevos casos de asma infantil y un aumento de la gravedad de los síntomas en niños que ya son asmáticos. Por consiguiente, se aconseja a los padres que rodeen a sus hijos de un ambiente sin tabaco y a los pediatras se les insta a investigar los hábitos tabáquicos de los padres cuando lleven a los hijos al consultorio después de la primera consulta posnatal.

Se ha demostrado en algunos estudios que la distancia física entre el niño y el padre fumador muestra una correlación con la cantidad de nicotina en la orina del niño; las concentraciones de nicotina urinaria son más bajas cuando los padres no fuman en la misma habitación donde se encuentra el niño. Por otra parte, mientras más bajas las concentraciones de nicotina urinaria, más bajo es el riesgo que corre el hijo de contraer infecciones respiratorias, según lo revelado por algunos estudios. A fin de investigar más a fondo los efectos de fumar cerca del niño sobre su salud respiratoria, un grupo de investigadores en Tasmania realizó un estudio de cohorte de 1988 a 1995 que abarcó a 11070 niños menores de un año. Durante el estudio los padres fueron entrevistados en tres ocasiones después del parto para investigar si fumaban, cuántos cigarrillos fumaba a diario la madre, y si la madre fumaba en la misma habitación donde estaba el bebé o mientras lo cargaba. También se obtuvo información de este tipo con respecto a otros miembros del hogar. En la última entrevista, que fue telefónica, se preguntó si el niño había sufrido catarros, infecciones en el pecho o amigdalitis. Al mismo tiempo se tomaron muestras de orina de 100 niños para determinar, mediante determinaciones de la concentración de nicotina, si era confiable la información proporcionada por los padres acerca de los hábitos tabáquicos en la familia. Se confirmó que sí lo era y se procedió a elegir una submuestra de 4486 niños del sur de Tasmania, a raíz de lo cual se revisaron las historias clínicas de hospitales de la localidad y, mediante un método de vinculación de fichas, se determinó que 416 niños de la muestra habían sido ingresados en algún momento por una infección respiratoria aguda. Se calculó el riesgo de dicha infección como el porcentaje de niños que fueron ingresados por una infección respiratoria aguda durante los primeros 12 meses de vida.

Según los resultados, en la cohorte estudiada $7,8 \%$ de los niños fueron hospitalizados por una infección respiratoria durante el primer año de vida. En la quinta semana posnatal, $48,6 \%$ de las madres fumaban y sus hijos menores de un año tenían un riesgo $50 \%$ mayor de padecer una infección respiratoria que los hijos de madres que no fumaban. El riesgo aumentaba en proporción con la cantidad de cigarrillos fumados al día por la madre y también en proporción con el número de fumadores en el hogar ( $P$ de la tendencia $<0,001)$, siendo mayor esta última tendencia, aunque no estadísticamente significativa, cuando la madre misma no fumaba. El riesgo aumentaba en relación directa con el número de cigarrillos fumados diariamente por otros miembros del hogar distintos de la madre $(P$ de la tendencia $=$ 0.036) y fue mayor en los hogares que tenían menos habitaciones por morador.

De las madres que fumaban, $71,8 \%$ dijeron que a veces o por costumbre fumaban en la misma habitación donde estaba el bebé, y esta conducta se observó con más frecuencia entre mujeres más jóvenes y entre las que fumaban un mayor número de cigarrillos al día. Los hijos de madres que fumaban en 
presencia del hijo tuvieron un riesgo $56 \%$ más alto de ser hospitalizados por una infección respiratoria que los de madres que fumaban pero que no lo hacían en la misma habitación donde estaba el bebé. El no fumar nunca en la misma habitación redujo en $70,6 \%$ el riesgo pronosticado cuando la madre a veces o por habitud fumaba en la misma habitación.

Las infecciones respiratorias observadas fueron de las vías respiratorias altas en 121 niños y de las bajas en 258. El aumento del riesgo en niños de madres que fumaban fue menor en el caso de las infecciones respiratorias superiores que en de las vías inferiores, pero los hijos de madres que fumaban en la misma habitación mostraron un riesgo aproximadamente igual de ambos tipos de infecciones.

En conclusión, el riesgo de infecciones respiratorias agudas de cualquier tipo es $50 \%$ mayor en hijos menores de un año de madres que fuman, pero si la madre observa buenos hábitos de higiene tabáquica y nunca fuma en la misma habitación donde se encuentra el niño, el riesgo se reduce de un modo significativo. Si estas asociaciones son de tipo causal, las madres que no pueden abandonar el hábito de fumar pueden, por lo menos, reducir la susceptibilidad de sus hijos a infecciones respiratorias agudas peligrosas procurando nunca fumar en la misma habitación. (Blizzard L et al. Parental smoking and infant respiratory infection: how important is not smoking in the same room with the baby? Am J Public Health 2003;93(3):482-494.)

\section{Las caries dentales en los niños y la exposición al humo de tabaco}

Las caries dentales son la enfermedad crónica más común en los niños, principalmente en aquellos que viven en condiciones de pobreza, aunque las razones no están bien definidas. Se trata de una enfermedad infecciosa que se debe a la colonización del dientes por Streptococcus mutans, bacteria que produce ácido láctico por fermentación de carbohidratos, con el resultado de que el ácido corroe la superficie dental. El motivo por el cual algunos niños son más susceptibles que otros no son del todo claras. Algunos autores opinan que la exposición a humo de tabaco en el ambiente, la cual se observa con mayor frecuencia en niños de clase socioeconómica baja, podría ser un factor de riesgo de caries dental. Esta creencia se basa en estudios anteriores en que se ha demostrado que el humo de tabaco se asocia con periodontitis en adultos y también en otras investigaciones que apuntan hacia un posible papel causal del humo de tabaco en la formación de caries. Para explorar esta hipótesis, un grupo de investigadores estadounidenses examinó datos transversales, obtenidos de la Third National Health and Nutrition Examination Survey (NHANES III) estadounidense, sobre 3873 niños entre las edades de 4 y 11 años a quienes se les había sometido a un examen dental y a mediciones de concentraciones de cotinina sérica, que fueron la principal variable independiente de interés. Se tomó como indicio de tabaquismo pasivo una concentración de esta última sustancia $\geq 0,2$ pero $<10 \mathrm{ng} / \mathrm{mL}$, siendo este punto de corte el que separa aproximadamente a la población fumadora en la que tiene una exposición al humo de tabaco por encima y por debajo de la mediana.

De los niños estudiados, 3531 tuvieron por lo menos un diente deciduo cariado y 2930 por lo menos un diente permanente con caries. En general, $53,1 \%$ de estos niños (2 057) tuvieron concentraciones de cotinina sérica compatible con la exposición al humo de tabaco; 46,7\% (1 809) tuvieron superficies dentales deterioradas o calzadas en dientes primarios, y $26,2 \%$ (1 015$)$ tuvieron superficies dentales deterioradas o calzadas en dientes permanentes. El análisis de dos variables mostró una asociación estadísticamente significativa entre las concentraciones séricas de cotinina y las caries en superficies dentales (razón de posibilidades $[R P]=$ 2,1; IC95\%: 1,5 a 2,9), y también entre dichas concentraciones y la presencia de calzas en los dientes $(\mathrm{RP}=1,4$; IC95\%: 1,1 a 1,8). Se observó, además, una asociación directa significativa entre la pobreza y la poca escolaridad y el riesgo de caries o dientes calzados. El ser de raza negra o de extracción mexicano-estadounidense también se asoció significativamente con un mayor número de superficies dentales cariadas pero con un menor número de dientes calzados. En el caso de la dentadura primaria, se observó una tendencia a un riesgo incrementado en relación directa con la concentración de cotinina sérica. Asimismo, esta concentración resultó ser un factor predictivo significativo del riesgo de caries en dientes primarios.

En el estudio no se detectó ninguna asociación significativa entre las concentraciones de cotinina y las caries en la dentadura permanente. No se puede descartar la posibilidad de que dichas concentraciones sean un simple marcador de alguna otra causa de caries dental, como podría ser, por ejemplo, la presencia de malas prácticas de higiene en hogares donde los padres fuman. El estudio también posee otras limitaciones, entre ellas la edad avanzada de los niños estudiados y su naturaleza transversal, cuando lo ideal sería saber las concentraciones de cotinina que tenían los niños antes de cumplir un año. No obstante, es la primera vez que se estudia en niños estadounidenses la asociación entre la exposición pasiva al humo de tabaco y el riesgo de caries dental. Es necesario efectuar más estudios que exploren esta 